\title{
Reversal of functional disorders by aspiration, expiration, and cough reflexes and their voluntary counterparts
}

\section{Zoltan Tomori ${ }^{1}$, , Viliam Donic ${ }^{1}$, Roman Benacka ${ }^{2}$, Sona Gresova ${ }^{1}$, Igor Peregrim ${ }^{1}$, Martin Kundrik $^{1}$, Maria Pallayova ${ }^{1}$ and Jan Jakus ${ }^{3}$}

${ }^{1}$ Department of Human Physiology, Faculty of Medicine, University of PJ Safarik, Kosice, Slovakia

2 Department of Pathophysiology, Faculty of Medicine, University of PJ Safarik, Kosice, Slovakia

${ }^{3}$ Department of Medical Biophysics, Jessenius Faculty of Medicine in Martin, Comenius University in Bratislava, Slovakia

Edited by:

Karen Wheeler-Hegland, University of Florida, USA

Reviewed by:

Karen Wheeler-Hegland, University of Florida, USA

Donald C. Bolser, University of

Florida, USA

*Correspondence:

Zoltan Tomori, Department of

Human Physiology, Faculty of

Medicine, University of PJ Safarik,

SNP av. 1, 04011 Košice, Slovakia.

e-mail: zoltan.tomori@gmail.com
Agonal gasping provoked by asphyxia can save $\sim 15 \%$ of mammals even from untreated ventricular fibrillation (VF), but it fails to revive infants with sudden infant death syndrome (SIDS). Our systematic study of airway reflexes in cats and other animals indicated that in addition to cough, there are two distinct airway reflexes that may contribute to auto-resuscitation. Gasp- and sniff-like spasmodic inspirations (SIs) can be elicited by nasopharyngeal stimulation, strongly activating the brainstem generator for inspiration, which is also involved in the control of gasping. This "aspiration reflex" (AspR) is characterized by $\mathrm{SI}$ without subsequent active expiration and can be elicited during agonal gasping, caused by brainstem trans-sections in cats. Stimulation of the larynx can activate the generator for expiration to evoke the expiration reflex (ExpR), manifesting with prompt expiration without preceding inspiration. Stimulation of the oropharynx and lower airways provokes the cough reflex (CR) which results from activating of both generators. The powerful potential of the AspR resembling auto-resuscitation by gasping can influence the control mechanisms of vital functions, mediating reversal of various functional disorders. The AspR in cats interrupted hypoxic apnea, laryngo- and bronchospasm, apneusis and even transient asphyxic coma, and can normalize various hypo- and hyper-functional disorders. Introduction of a nasogastric catheter evoked similar Sls in premature infants and interrupted hiccough attacks in adults. Coughing on demand can prevent anaphylactic shock and resuscitate the pertinent subject. Sniff representing nasal inspiratory pressure and maximal inspiratory and expiratory pressures (MIP and MEP) are voluntary counterparts of airway reflexes, and are useful for diagnosis and therapy of various cardio-respiratory and neuromuscular disorders.

Keywords: aspiration reflex, breathing maneuvers, expiration reflex, functional disorders, urge-to-cough

\section{INTRODUCTION}

The gradual development of gasping in infants dying of sudden infant death syndrome (SIDS) has been detected by cardio-respiratory monitoring (Thach et al., 1989b; Wulbrand

Abbreviations: 5HT, 5 hydroxy tryptamine; AspR, aspiration reflex; BAEP, brainstem acoustic-evoked potentials; CBF, cerebral blood flow; $\mathrm{CD}$, cardiac death; COPD, chronic obstructive pulmonary disease; CPCR, cardio pulmonary cerebral resuscitation; CR, cough reflex; CSA, central sleep apnoe; DI, deep inspiration; ECG, electrocardiogram; EEG, electroencephalogram; EMG, electromyogram; EMS, expiratory muscular strength; EMST, expiratory muscular strength training; ExpR, expiration reflex; $\mathrm{FEV}_{1}$, forced expiratory volume/s; fMRI, functional magnetic resonance imaging; HBEFR, Hering-Breuer expiration facilitating Reflex; HBIR, Hering-Breuer inflation reflex; GG, genioglossus; IMST, inspiratory muscular strength training; IN, inspiratory neurons; MEP, maximal expiratory pressure; MIP, maximal inspiratory pressure; NPh, nasopharynx; NSRF, nucleus sub retro facialis; OSA, obstructive sleep apnoe; PD, Parkinson's disease; Ppl, pleural pressure; preBötzC, preBötzinger complex; RARs, rapidly adapting receptors; SARs, slowly adapting receptors; SDB, sleep disordered breathing; SI, spasmodic inspiration; SIDS, sudden infant death syndrome; SNIP, sniff nasal inspiratory pressure; UAs, upper airways; UANPR, upper airway negative pressure reflex; UARS, upper airway resistance syndrome; V', airflow; VF, ventricular fibrillation; $\mathrm{V}_{\mathrm{T}}$, tidal volume. et al., 1995). Gasping also develops regularly in pigs and other animals during untreated experimental ventricular fibrillation $(\mathrm{VF})$ after $\sim 5$ min (Xie et al., 2004). Such gasping can auto-resuscitate some of these animals (Thach et al., 1991; Thach, 2005). Clinical studies indicated that occlusion of a face-mask outlet at the end of inspiration for several seconds in infants during sleep, after transient inhibition gradually enhanced diaphragmal activity and caused a negative pressure in the mask. After development of hypoxia and hypercapnia a sigh occurred regularly. The augmented part of sigh was always accompanied with a startle reaction, manifesting with activation of the nuchal and limb muscles, which caused reopening of upper airways (UAs) in both REM and non-REM sleep. The startle reaction was usually accompanied with a micro-arousal lasting $<3 \mathrm{~s}$, the intensity of which correlated with a simultaneous heart rate acceleration. These results indicate that opening of the UAs by a sigh and startle can be realized by brainstem reflexes without cortical arousal (Wulbrand et al., 2008). Strong stimulation in healthy infants evokes a gasp, often resulting in auto-resuscitation by gasping (McNamara et al., 
2002). Similar occlusive events occurring in babies at risk for SIDS during a critical period of development (mostly in 1st year) does not evoke a sigh, startle, or gasp, but results in silent death, as illustrated schematically (Figure 1).

Monitoring of infants during sleep indicated that occlusion of the face-mask outlet represents a strong stimulus, causing hypoxemia and hypercapnia. This was accompanied by sighs and gasps, often resulting in auto-resuscitation by gasping. Therefore, the explanation of the mechanisms of the auto-resuscitation by gasping appeared to be extremely important from both theoretical and practical points of view. Negative pressure applied to UAs strongly increases the inspiratory drive during sleep. More negative pressure than $-12 \mathrm{~cm} \mathrm{H}_{2} \mathrm{O}$ in the UAs induce a "pharyngeal dilatory reflex" (Thach et al., 1989a). Similar gasp- and sniff-like spasmodic inspirations (SIs), the so-called aspiration reflex (AspR) can be regularly induced by mechanical contact, pressure pulses, and electrical stimulation of the nasopharynx (NPh) in cats (Tomori and Widdicombe, 1969; Tomori, 1979b; Tomori et al., 2000, 2010). AspR has a powerful revitalization potential manifesting with reversal of hypoxic apnoea, asphyxia, and even a comatose state (Tomori et al., 1991, 1995a, 2000). Therefore, our aims were: (1) To analyze the effects of AspR and other airway reflexes for reversal of functional disorders in animals, and (2) to discuss the existence and applicability of airway reflexes and their voluntary counterparts (sniffs + prompt expirations) in the diagnostics and therapy of several cardio-respiratory and neuromuscular disorders in patients.

\section{REFLEX MODIFICATIONS OF BREATHING UPPER AIRWAY NEGATIVE PRESSURE REFLEX}

The upper airway negative pressure reflex (UANPR) is present in both animals and humans. Its afferent pathways were studied using anesthesia of UAs (Horner et al., 1991a,b). The reflex can change the lumen of UAs by activation of dilatory muscles: m. genioglossus (GG) and $\mathrm{m}$. tensor palatini. Negative pressure pulses $\left(-10 \mathrm{~cm} \mathrm{H}_{2} \mathrm{O}\right.$ lasting for $250 \mathrm{~ms}$ ) during early inspiration in healthy men can evoke a short-latency activation followed by a suppression of the GG EMG in wakefulness and sleep. The valvular function of UAs relate both to airway patency (measured by pharyngeal resistance) and anatomical airway narrowing/collapsibility (reflected by positive end-expiratory pressure). In addition to primary activation the UANPR also induces a secondary inhibition of the GG muscle activity (67.8\% of baseline), with a latency of $71 \pm 4 \mathrm{~ms}$ in $35 \%$ of healthy subjects (Eckert et al., 2007, 2010). The aim of such secondary inhibition is probably to prevent an aspiration of the secretion into the lungs, allowing UAs collapsibility and modification of the diaphragmal activity.

\section{DEFENSIVE AIRWAY REFLEXES}

Breathing and other vital functions are strongly influenced by various airway reflexes, including mainly coughing, and two other distinct reflexes, that have been systematically analyzed over multiple decades. A multifunctional respiratory pattern generator undergoes reconfiguration to produce cough and other airway defensive behaviors. Behavior selective neurons may be

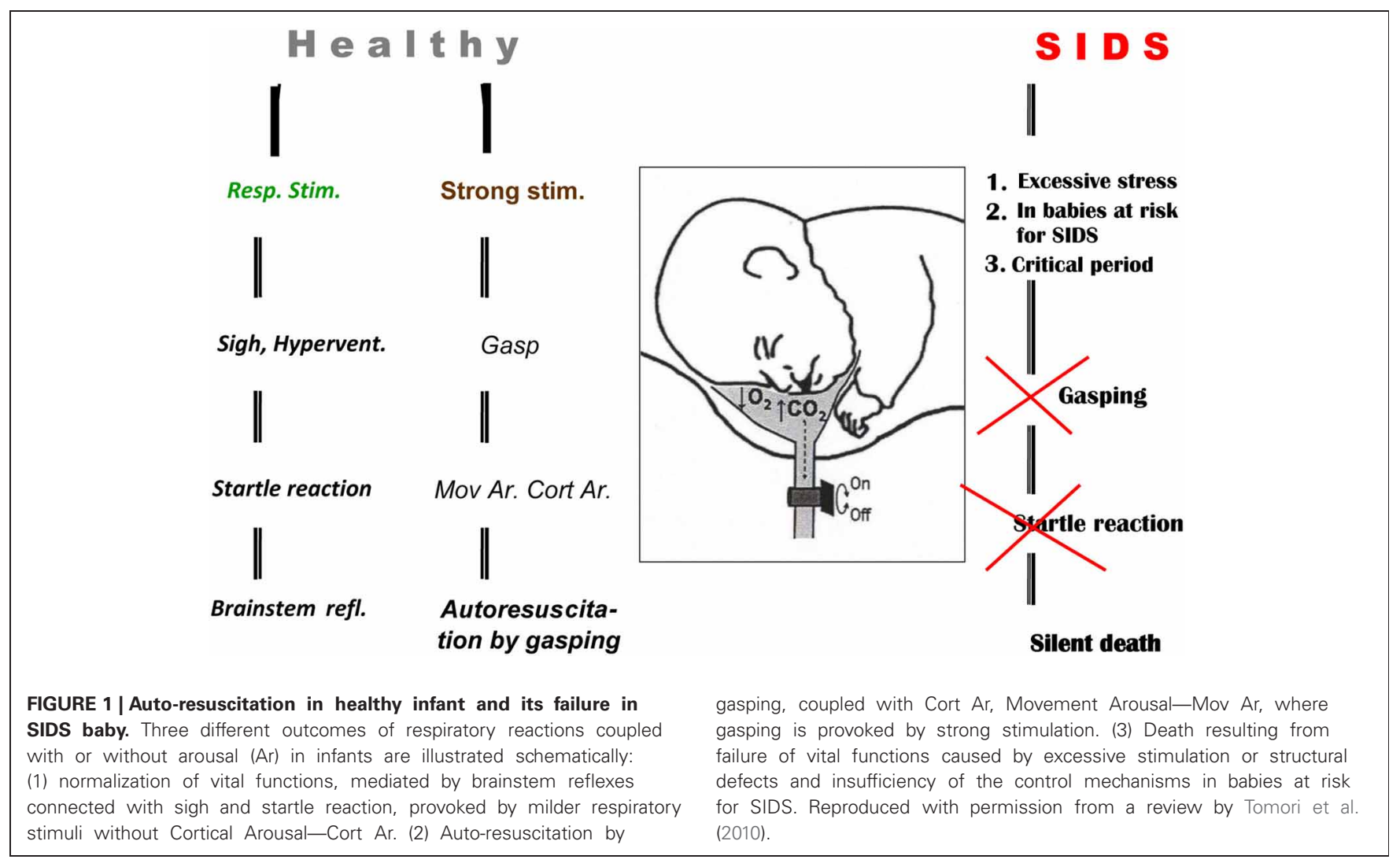


responsible for regulating the function of core pattern generating network to allow it to mediate multiple tasks, including amplification of the motor drive. Such task may be rhythmic as breathing and swallowing or highly patterned reactions such as cough, expiration, and AspRs (Bolser et al., 2006). Pre-Bötzinger complex (preBötzC) is necessary and sufficient for generating inspiratory rhythm. This produces normal respiratory activity (eupnea) and sighs under normoxic conditions, but gasping during hypoxia after a reconfiguration process. The reconfiguration involves changes in synaptic and intrinsic properties of neurons that can be mediated by several neuromodulators, including 5HT and substance $\mathrm{P}$ (SP). Neuromdulation provided mainly by glial cells are important for rhythmogenesis of preBötzC. Continuous neuromodulation tunes the excitability of the preBötzC to respond to different demands and also determines the weight of specific neuronal types or specific synaptic interactions with generation of network dynamics (Pena-Ortega, 2012). The extremely high excitability of inspiratory generator can explain the constant elicitability of strong gasp-like AspR by nasopharyngeal stimulation. It is a very important observation that each mechanical contact stimulation of the NPh during agonal stage in cats evokes even stronger gasp-like AspR than the spontaneous agonal gasp (Tomori, 1979b).

Figure 2 schematically illustrates the 10 main components of the three most important defensive airway reflexes compared to quiet breathing (Tomori et al., 2010). The cough reflex (CR), held as the "watchdog of the lungs" is induced mostly by stimulation of rapidly adapting receptors (RARs) from the tracheal-bronchial region. It consists of three phases and manifests with strong inspiratory and expiratory efforts (Korpas and Tomori, 1979; Jakus et al., 2004b; Widdicombe, 2006, 2011). During the initial deep inspiration (DI), the gradually increasing lung volume stimulates the slowly adapting receptors (SARs) of airways and via the Hering-Breuer inflation reflex (HBIR) induces the expiratory period, starting with the compressive phase. After glottal closure and rapid compression of the enlarged lung volume via the so-called Hering-Breuer expirium facilitating reflex (HBEFR) provokes strong expiratory effort (Marek et al., 2008), manifesting during the expulsive phase of CR. In addition to the HBIR and HBEFR, the proprioceptive reflexes of the respiratory muscles and stimulation of RARs, SARs, $A_{\delta}$, and C-fibers in the airways and lungs in non-paralyzed subjects, can also

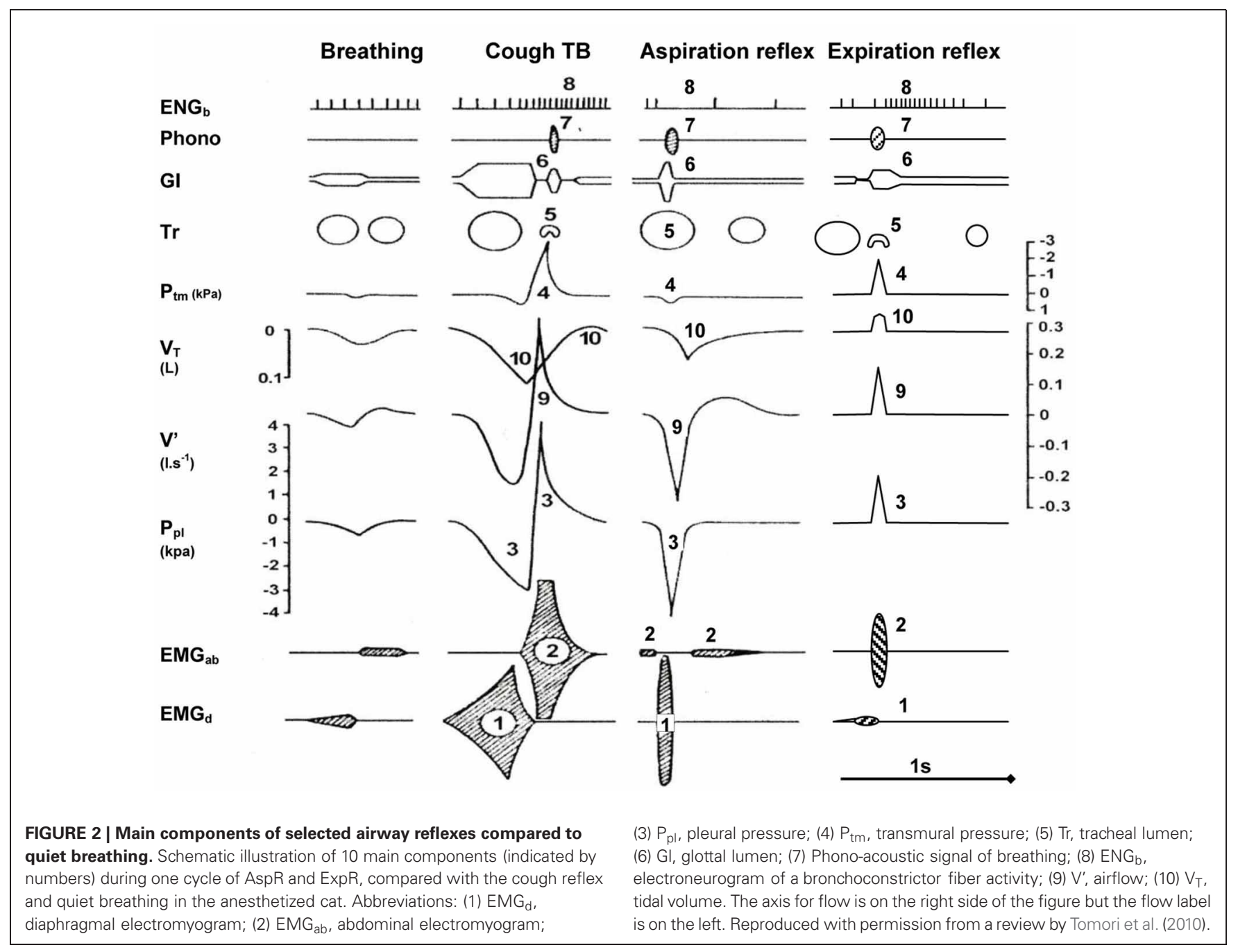


contribute to the modification of cough efforts (Korpas and Tomori, 1979; Widdicombe, 2006, 2011; Widdicombe et al., $2011 \mathrm{a}, \mathrm{b})$. Studies in guinea pigs suggest that a previously unrecognized subtype of airways afferent nerve-cough receptors-play the primary role in regulating this defensive reflex. These putative cough receptors are myelinated and do not synthesize and express neuropeptides under normal conditions (Canning and Mazzone, 2005). Experiments in rabbits and dogs suggest a significant role also for slowly adapting airway receptors in CR (Sant'Ambrogio et al., 1984).

Mechanical stimulation of the larynx in animals and humans evokes the expiration reflex (ExpR), characterized by prompt expiratory effort without preceding inspiration (Korpas, 1972, 1979; Tatar et al., 2008). When provoked during a spontaneous inspiration, ExpR, contrary to $\mathrm{CR}$ immediately interrupts the present inspiration, and evokes laryngo-constriction to prevent aspiration of the irritants into the lower airways and the lungs and expels them promptly by strong expiratory effort (Tomori et al., 2010; Widdicombe et al., 2011a). ExpR, similarly to CR is accompanied by bronchoconstriction in addition to laryngeal closure. On the contrary, AspR is accompanied by a dilation of the upper and lower airways (Figure 2).

Mechanical, electrical, and other methods of stimulation of the $\mathrm{NPh}$ in cats and most mammals regularly evoke a sniffand gasp-like AspR (Tomori, 1965, 1979b; Donic et al., 1992). It manifests as a solitary SI that lasts only for $150-230 \mathrm{~ms}$ in the diaphragmal EMG and airflow records and is usually not followed by an immediate active expiration (Benacka and Tomori, 1995; Tomori et al., 1995b, 1998). The tendency to SI decreases gradually from the beginning of the inspiratory phase of breathing (Marek et al., 2008), probably reflecting the respiratory drive. Similar SIs were observed after induction of a nasogastric catheter for feeding also in premature infants (Javorka et al., 1980). In paralyzed cats, stimulation of the "irritant" RARs of the NPh by mechanical contact or pressure pulses evokes a very strong activity in glossopharyngeal afferents. The high frequency of impulses (mean 197/s, range 56-330), (Nail et al., 1969) strongly activates many inspiratory neurons in the brainstem (Jakus et al., 2004a,b), probably also including inspiratory neurons in the preBötzC, described recently as "the generator for inspiration" in rats (Janczewski and Feldman, 2006a,b). AspR and ExpR provide very strong separate reflex activations of the two distinct brainstem generators for inspiration and expiration with simultaneous reciprocal inhibition. Therefore, they provide a unique methodological basis for their practical applications in animal and clinical studies.

\section{Specific characteristics and mechanisms of AspR}

In a recent review of reflexes from the upper respiratory tract (in Comprehensive Physiology; Widdicombe, 2011) Widdicombe stated that the UA reflexes were extensively analyzed in a monograph by Korpas and Tomori (1979). He indicated that this book was the first work to study the AspR comprehensively, completing two basic papers (Tomori, 1965; Tomori and Widdicombe, 1969) in addition to cough and ExpRs. This reaction was later described as the sniff reflex (Batsel and Lines, 1973), but the distinction between sniffing induced by odors inhaled into the nose and AspR from the NPh is not very clear. This reaction was analyzed from 1994 also by Japanese researchers as a hiccuplike reflex (as discussed later). In a recent review, Widdicombe (2011) stated that AspR in cats is exceptionally resistant against anesthesia, hypothermia, asphyxia, and could be important in reanimation. This exceptional resistance is based on the fact that AspR can be evoked in anesthetized cats even after total brainstem transection $5 \mathrm{~mm}$ above the obex in the agonal state after elimination of the ExpR and CR and replacement of breathing by gasping respiration (Jakus et al., 1987, 2004a,b). Reflex recruitment of medullary gasping mechanisms can be induced by pharyngeal stimulation in cats during eupnea (Fung et al., 1994; Tomori et al., 1995a, 2010).

The specific character and the complex effects of AspR are schematically illustrated in Figure 3. It indicates that AspR can be evoked in any phase of the respiratory cycle in a cat. It replaces the spontaneous inspiration or expiration by a rapid and strong spasmodic inspiratory effort and UA dilation, caused by strong activities in the phrenic and superior laryngeal nerves, and bulbar inspiratory neurons. It can also replace strong tonic expiratory activities in the lumbar and laryngeal recurrent nerves. Also, bulbar expiratory and inspiratory activities can be suppressed

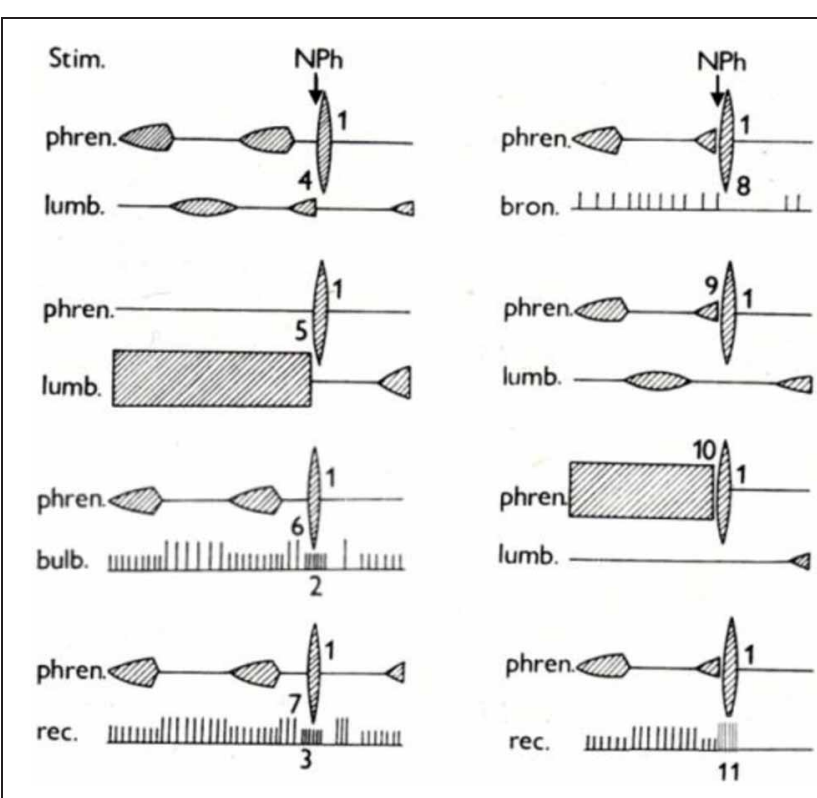

FIGURE 3 | Specific activity in various neural structures evoked by NPh stimulation in cats. Schematic illustration of changes evoked in activity of motoneurones of the phrenic nerve (phren.), lumbar nerve (lumb.), and recurrent laryngeal nerve (rec.), of bulbar inspiratory and expiratory neurons (bulb.) and of bronchoconstrictor fiber of vagus (bron.) by mechanical stimulation (Stim.) of nasopharynx (NPh) in anesthetized cats. The numbers indicate development of specific activity in the phrenic nerve (1), in inspiratory neurons of medulla oblongata (2) and in inspiratory neurons of recurrent laryngeal nerve (3) during expiration. Inhibition of spontaneous (4) and tonic (5) expiratory activity in the lumbar nerve, bulbar expiratory neurons (6), and recurrent laryngeal nerve (7) during expiration. Inhibition of bronchomotor fibers of vagus (8). Replacement of spontaneous (9) and tonic (10) inspiratory activity in the phrenic nerve and recurrent laryngeal nerve (11) by specific activity during inspiration. Adapted from Tomori et al. (1976). 
and replaced, and the bronchoconstrictor nerve activity can be inhibited by the powerful activity of AspR. These effects suggest practical applicability of AspR for inhibition of unwanted effects of coughing, asthmatic attacks, spastic events, etc.

Cine-photography of the glottis and parallel recording of instantaneous pleural pressure $(\mathrm{Ppl})$ of one cycle of typical AspR in a cat are compared with other airway reflexes in Figures 4, 5. The data indicate that in AspR, the rapidly starting maximal inspiratory $\mathrm{Ppl}$ is more negative and the trans-glottal diameter and glottal area are similar, than during the inspiratory phase of CR. During the second part of the cycle, the trans-glottal diameter and glottal area in AspR decreased in parallel with the decrementing negative $\mathrm{Ppl}$, causing some acoustic signal. However, contrary to the cough and sneeze, there is no total closure of glottis or active expiration, similar to quiet expiration. In spontaneous gasp and AspR provoked by NPh stimulation, there is a tendency for maximal contraction of the inspiratory muscles of all or nothing type with a simultaneous inhibition of expiratory muscle activity and rapid glottal opening. These activities tend to supply oxygen to the lungs and also enhance the venous return of blood to the heart, due to a strong negative intrathoracic pressure. They support the perfusion of the myocardium and brain. Therefore, they can prevent an imminent loss of consciousness and promote the auto-resuscitation (Tomori, 1979b; Tomori et al., 2010). A transient activation of the laryngeal adductor muscles prior to a strong glottal dilation and powerful diaphragmal activity, tend to stiffen the UA wall to prevent collapse and total closure of glottis (Tomori, 1979b; Poliacek et al., 2003).

\section{The hiccough-like reflex}

A reaction very similar to the sniff- and gasp-like AspR (illustrated in Figures 4, 5) was later analyzed by Japanese authors in cats and described independently as a hiccough-like reflex. This reaction was elicited from the epipharyngeal area (Oshima et al., 1994). It also has a glosso-pharyngeal afferent pathway (Kondo et al., 2003) and involves similar brainstem inspiratory neurons (Arita et al., 1994). In addition it has also a very powerful inspiratory activity (Oshima et al., 1998) as the AspR analyzed by us. In this hiccoughlike reflex, there was a glottal closure, presumably caused by a secondary reflex suppression in genioglossal muscle activity observed by Eckert et al. (2010), as a response to the UANPR. The AspR resembles a gasp and sniff, rather than hiccough, as shown by the difference in the acoustic signal and the lack of total expiratory closure of glottis, documented in Figures 4, 5, adapted from our monograph (Korpas and Tomori, 1979).

Hiccough caused very serious diagnostic and therapeutic problems, indicated in $\sim 2000$ contributions according to a search on terms "hiccough," "hiccup-like reflex," and "singultus" using PubMed. Hiccough can be evoked in $40 \%$ of healthy participants by rapid distension of the upper part of esophagus with a balloon inflated with $40 \mathrm{ml}$ air for $1 \mathrm{~min}$, representing a pressure of $64 \mathrm{mmHg}$ (Fass et al., 1997). The functional role of hiccough is not clear (Kahrilas and Shi, 1997). The distressing hiccough attacks in patients, however, can be interrupted by introduction of a nasogastric catheter to the cervical region (Salem et al., 1967), provoking probably a gasp-like reaction. An even more practical and truly working method for hiccough interruption is

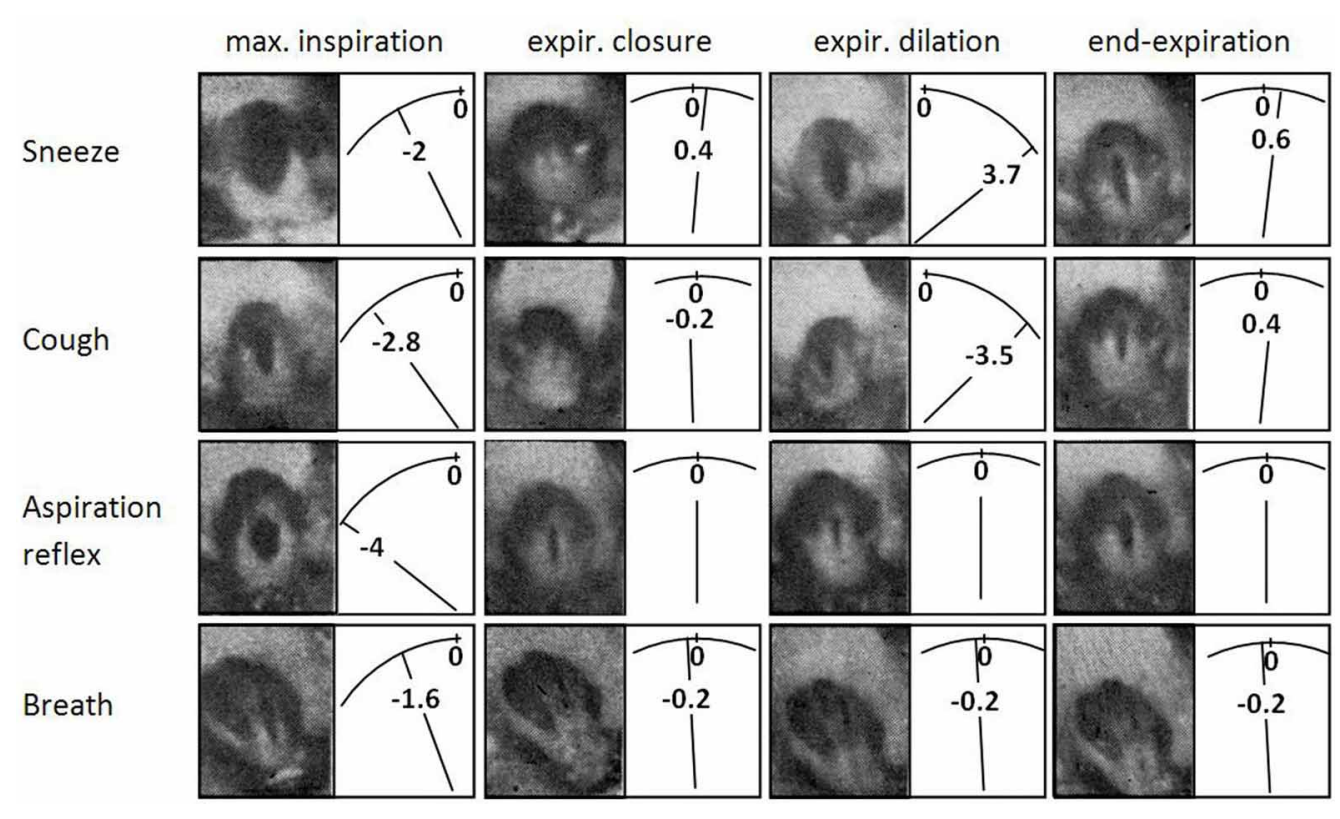

FIGURE 4 | Cine-photographs of glottis in sneeze, cough, AspR, and control breath in a cat. Cine-photographs of glottis in one inspiratory-expiratory cycle of the sneeze, cough from tracheo-bronchial region, aspiration reflex, and control breath in anesthetized cat. Phases illustrated: maximum inspiration, early expiratory glottal closure or narrowing, successive expiratory glottal dilation, and end of expiratory phase. Instantaneous pleural pressure $\left(P_{p l}\right)$ values were recorded in parallel, are illustrated diagrammatically and expressed in $\mathrm{kPa}$ to the right of each picture. The figure was reproduced with permission from a chapter "Tomori: The Physiology of the cough reflex, 1979a," in a monograph "Korpas and Tomori: Cough and Other Respiratory Reflexes," published by Karger in Basel. 
swallowing of $400 \mathrm{ml}$ cold water, combined with a tight pressure on tragi of ears inward to completely seal the external acoustic meati while the patients simultaneously drink all the water through a straw. By the end of this maneuver, the hiccoughs should have resolved (Goldstein, 1999).

\section{Gasp-like reactions to stimulation of highly sensitive superficial points}

Similar sigh- and gasp-like SIs resembling AspR, being evoked by stimulation of the NPh, can be provoked by stimulation of several highly sensitive superficial locations as well. Three devices and methods are now being used by us for reversal of several functional disorders, not caused by irreversible structural alterations or chronic pathological processes. A series of such SIs are accompanied by activation of the sympathetic nervous system, resulting in tachycardia, vasoconstriction, and hypertensive reaction, but also with signs of Micro-Arousal characterized by 1.5-3 s alpha rhythm in EEG and brainstem acoustic-evoked potentials (BAEP). Such SIs evoked by stimulation of nasal filter can repeatedly interrupt severe hypoxic apnea and even a developing comatose state in anesthetized cats (Benacka and Tomori, 1999).

\section{CHARACTERIZATION OF VARIOUS TYPES OF DEEP AND SPASMODIC INSPIRATIONS}

There are many types of inspiration, where the activity of respiratory muscles, valvular function of the glottis, the airflow rate, and the inspired volume differ but are pertinent to the behavioral task. DI is usually the first phase of $C R$, substantially increasing the successive expiratory effort (Tomori and Widdicombe, 1969; Tomori, 1979a; Marek et al., 2008) as discussed earlier. A sniff promoting olfaction requires a short-lasting rapid inspiration with a strong

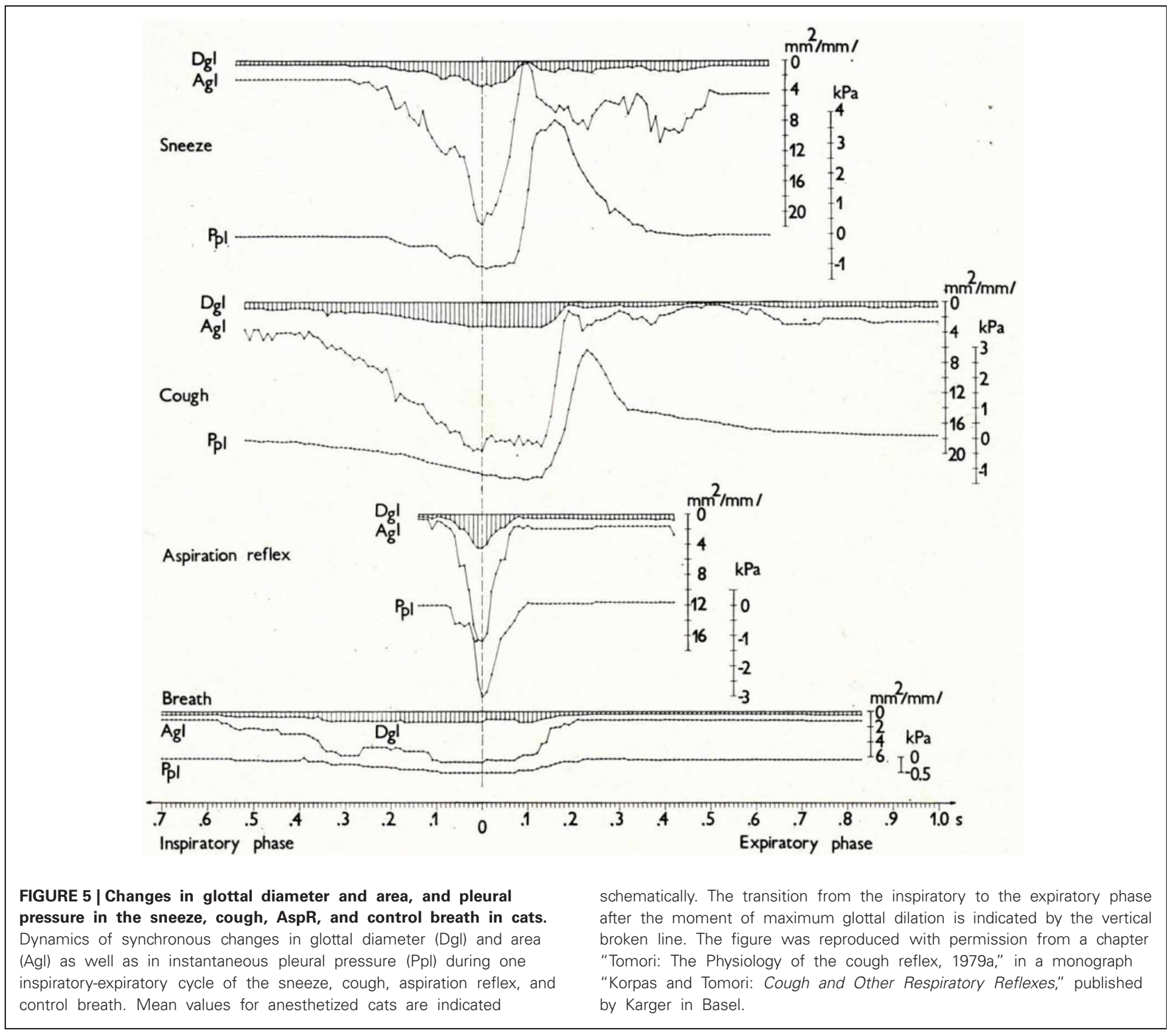


but transient glottal opening and a moderately augmented tidal volume. This is necessary for the transport of odorants with airflow mainly to the olfactory receptors in the upper part of nasal cavity, but not to the lungs. At small concentrations of the odors, the inspired volume increases automatically to compensate for the low intensity of olfactory stimulation by an increase in volume. In hiccough, there is a late-inspiratory sudden glottal narrowing, accompanied by a typical acoustic phenomenon. This is caused by movement of inspired air through the decreasing glottal area, preventing larger lung inflation, in spite of the strong spasmodic twitch of inspiratory muscles (Newsom Davis, 1970).

Schematic Figure 6 indicates various forms of respiratory efforts, connected with different degrees of arousal reactions, mediated by variable neural substrates. In the figure, the negative $(-)$ and positive $(+)$ effects of these arousal reactions in humans, are compared with AspR induced by nasopharyngeal stimulation in cats. Milder sleep-related breathing disorders, such as snoring and upper airway resistance syndrome (UARS), accompanied by Micro-Arousal or short-Arousals mainly tend to normalize the separate transient disorders of vital functions. In sigh, there is a second augmented part, representing a SI with a wide opening of the glottis. This allows lung inflation with distension of the atelectatic regions, which can persist. More severe degrees of sleep disordered breathing (SDB), often connected with asphyxia are accompanied by Macro-Arousal and causing solitary gasps. Gasps may normalize breathing, resulting in adaptation to hypoxia by preconditioning. Progressive hypoxia and asphyxia may result in auto-resuscitation by development of periodic gasping. However, the airway protective reflexes, mainly the cough, ExpR, and swallowing, as well as general defense mechanisms including muco-ciliary transport, antibacterial and antiviral defense, alveolar macrophages, may fail. Then the persisting gasps may contribute to development of a sinobronchial syndrome or aspiration pneumonia (Addington et al., 2003, 2005; Widdicombe et al., 2011a). Also severe nocturnal cardiac arrhythmias may develop in patients with SDB and their occurrence correlates with intensity of sleep apnea in men (Szaboova et al., 2013). Even a sudden cardiac death may occur, particularly in elderly patients and during frequent respiratory infections.

The AspR induced by stimulation of NPh in cats activates many brainstem inspiratory neurons, and generates a gasping-like activity (Fung et al., 1994; Tomori et al., 1995a). Some of these neurons were recently specified as the "generator for inspiration," in the medullary preBötzC of neonatal rats (Janczewski and Feldman, 2006a,b). AspR can influence also the central mechanisms of

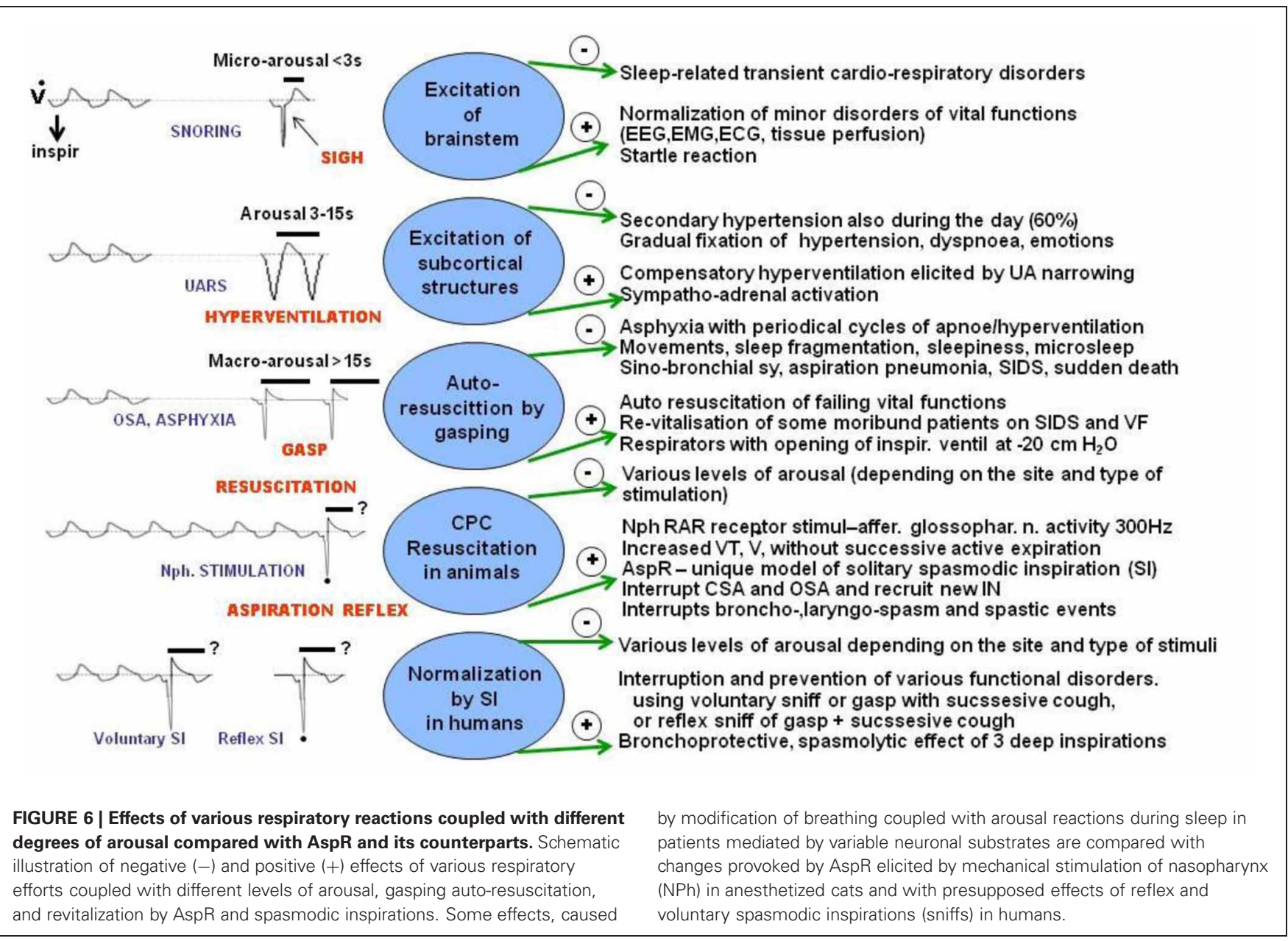


various vital functions through dense synaptic connections in rats (Tan et al., 2008, 2010), as well as in cats (Jakus et al., 2004b). Therefore, AspR could interrupt various cardio-respiratory and neurobehavioral disorders of functional character (Tomori et al., 2010), via influencing 14 of 35 nuclei identified in the brainstem of cats (Jakus et al., 2004a).

\section{REVITALIZATION EFFECTS OF DEEP AND SPASMODIC INSPIRATIONS AND PROMPT EXPIRATIONS}

The three airway reflexes very strongly activate the two brainstem generators (Figure 7) and can directly modify (facilitate or inhibit) the "central control mechanisms" of various vital functions (Tomori et al., 2010). They are very effectively mediated by dense synaptic connections (Tan et al., 2010) and various mediators. Such "overdrive activation of the inspiratory generator" caused by NPh stimulation provokes AspR, which might provide a unique chance to reset the control mechanisms, primarily of three vital functions (breathing, cardio-vascular, and neuromuscular activities). This might promote normalization of hypo- and hyper-functional disorders, if not hindered by the presence of severe or fixed changes (e.g., acute stroke or recent myocardial infarction), both in animal experiments and probably also in human studies. AspR and $\operatorname{ExpR}$ reversed several life-threatening disorders of functional character, manifesting as apnea termination, and resuscitation in cats (Tomori et al., 2000). Power spectral analysis of the phrenic and the hypoglossal nerve activity in paralyzed cats indicated very similar peaks during both the hypoxic gasping and AspR, evoked by NPh stimulation (Fung et al., 1994; Tomori et al., 1995a,b), resembling auto-resuscitation by gasping. Therefore, the powerful AspR might influence positively the imbalance between the excitatory and inhibitory cardio-respiratory reflexes responsible for survival or death in the patho-mechanism of SIDS, according to the hypothesis of Leiter and Böhm (2007).

Sniff-like AspR, ExpR, and CR, as well as the UA negative pressure reflex, and particularly their voluntary counterparts, the sniff plus forced expiration, have complex central control mechanisms. Their interaction and support by behavioral and pharmaceutical methods might have a great practical importance.

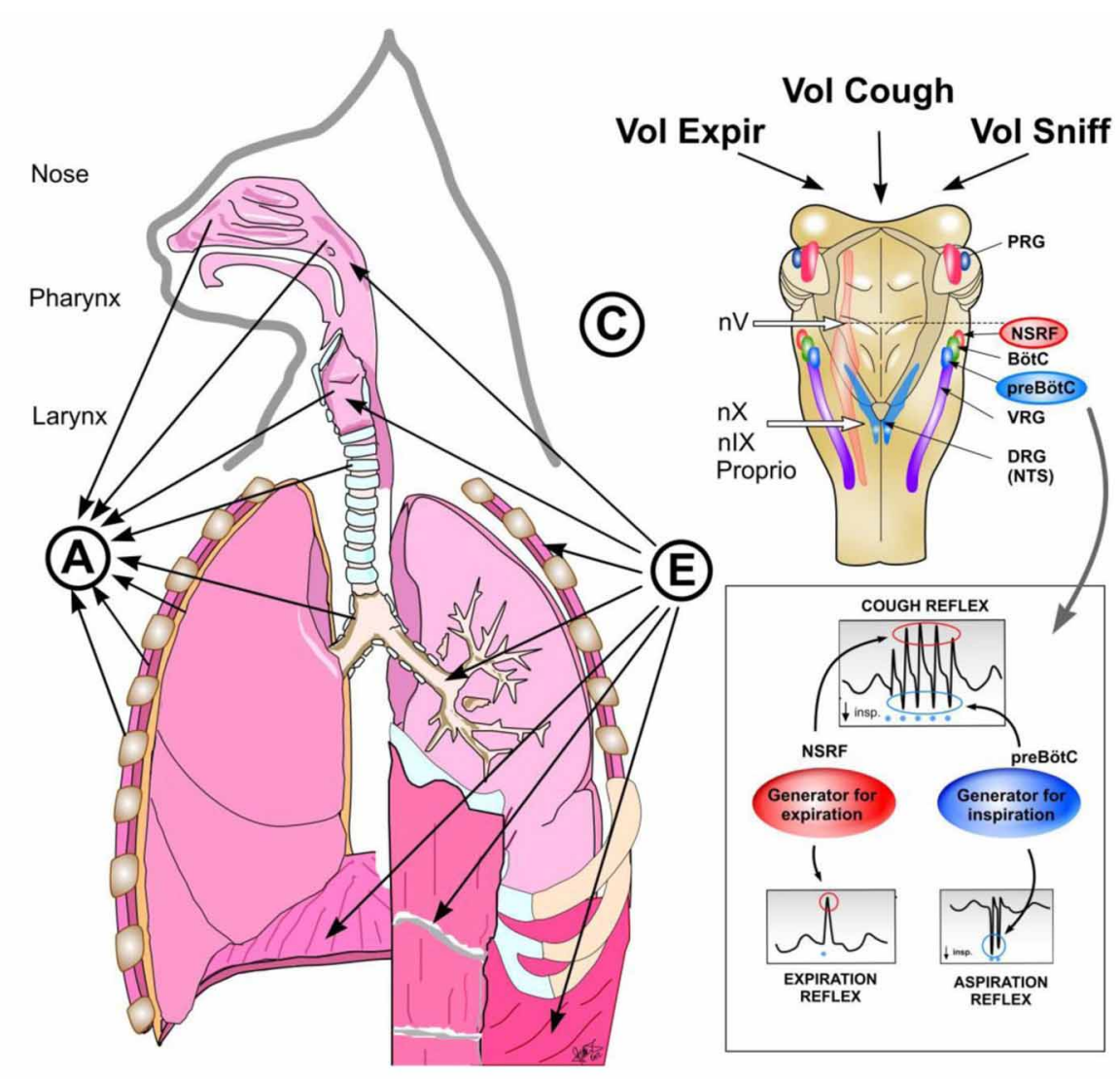

FIGURE 7 | Reflex arch and mechanisms of AspR, ExpR, and CR and their voluntary counterparts. Schematic illustration of reflex arch and mechanisms of AspR, ExpR, and CR and their voluntary counterparts. A-afferents via trigeminal nerve from the upper part of nasal cavity for sniffing, via n. glosso-pharyngicus from the nasopharynx for AspR, via $\mathrm{n}$. laryngicus sup. from the larynx for ExpR and via $\mathrm{n}$. vagus from tracheal-bronchial region and proprioceptive afferents for CR. E-efferents to inspiratory muscles (diaphragm and external intercostals) and to expiratory muscles (abdominal and internal intercostals) for ExpR and CR. C-central structures: Generator for inspiration in preBötzinger complex for AspR, generator for expiration in NSRF for ExpR and both generators for CR. Breathing maneuvers allow voluntary performance of all three reflexes (voluntary sniffs, prompt expiration, and sniff followed by strong expiration), which have perspective clinical applications. 
AspR often has a multi-phasic character, manifesting with several repetitive SIs, particularly in cases of hyperreactivity or frequent intensive natural or experimental stimulation. It resembles the multiple "double" and "triple" gasps, observed frequently in moribund infants with SIDS (Sridhar et al., 2003; Wulbrand et al., 2008). Similarly, 2-3 successive active expirations without interposed inspirations may manifest as separate ExpRs in a cough attack, occurring occasionally in cats with experimental bronchitis (Korpas, 1979). Many functional disorders might be modified by SIs, induced by nasopharyngeal stimulation or by various other methods of SIs provocation. Different patho-physiological conditions could also be normalized, by using AspR and ExpR directly, or through the dense synaptic connections of the brainstem "inspiratory generator," and "expiratory generator" or by a variety of neuromodulators. However, breathing is a kind of voluntary somato-motor activity that depends on the integration of a chemosensory drive, arising from the central and peripheral chemoreceptors with dynamic feedback from airway afferents and with the respiratory rhythm generator (McCrimmon and Alheid, 2007). In this complex control mechanism, the airway reflexes and particularly the AspR may have an important restorative and lifesaving contribution and their applicability and mechanisms have to be tested both in animal experiments and clinical studies.

Stimulation of the larynx both in cats and humans strongly activates the higher located generator for expiration causing laryngo-constriction and prompt expiratory effort without preceding inspiration. This prevents intrusion of secretions and irritant materials into the lungs and supports their expulsion. Stimulation of the tracheo-bronchial mucous membrane activates both the inspiratory and expiratory generators provoking DI followed by a powerful expiratory effort for prevention of aspiration into the lungs. It also provides venous return to the heart and supports brain perfusion preventing and terminating various collapsible states. Therefore, AspR as a model of SIs alone or combined with forced expiration (ExpR) or prompt voluntary cough effort (without preceding inspiration) can serve to reverse many dysfunctional states. These "on demand" provocations could be very useful for the study of cardio pulmonary cerebral resuscitation (CPCR) in model experiments with dysrhythmias, including VF, particularly in pigs, cats, mini pigs, and in rats. Already spontaneous gasps restored the cerebral blood flow (CBF) to $59 \%$ of the control values. There was a very significant correlation of CBF with decreases in intrathoracic pressure during the inspiratory phase of gasps and with the increases of aortic pressure during the expiratory phase of gasps. Spontaneous gasps producing significant increases in the CBF during untreated cardiac arrest, confirmed the beneficial resuscitative effect of gasping during the cardiac arrest (Ristagno et al., 2007). Similarly, reversal of many other patho-physiological conditions, indicated in Figure 6, could be tested by using AspR and ExpR or their voluntary counterparts.

In $\operatorname{ExpR}$ there is a very positive correlation between the lung inflation volume and pressure, provoked during the expiratory period of the respiratory cycle (Poliacek et al., 2008). This relation can be explained by HBEFR, which is very strong at the beginning of the expiratory period, reflecting the momentary large lung volume (Marek et al., 2008). In addition to strong gasp-like inspirations provoked by NPh stimulation and mediated by brainstem central control mechanisms participating in gasping, the AspR is also characterized by reciprocal inhibition of expiratory activity. Experiments in paralyzed cats, however, allow evaluation of persisting reflex effects of the "fictive AspR" (Shiba et al., 1999). Vegetative reflex tachycardia and vasoconstriction evoked by fictive AspR may at least partially support auto-resuscitation after myo-neural blockade supporting venous return to the heart and brain.

In a similar manner, 2-3 voluntary rapid and strong sniffs, each followed by a prompt forceful expiratory effort, may prevent an imminent loss of consciousness. They may even resuscitate the subject, resembling auto-resuscitation by gasping (Figure 6). In addition to cardiovascular applications aimed to treat severe morbid cases and prevent a sudden cardiac death, a combination of AspR, supporting venous return and ExpR, or a prompt cough effort, increasing cerebral perfusion, provide a simple but unique model tested by us now both in animal experiments and human studies.

\section{CORTICAL AND SUB-CORTICAL MECHANISMS OF AIRWAY REFLEXES AND BREATHING MANEUVERS DIAGNOSTIC AND THERAPEUTIC APPLICATIONS OF AIRWAY REFLEXES AND RESPIRATORY MUSCLE STRENGTH MEASUREMENT}

The strength of the protective and expulsive efficacy of airway reflexes is frequently measured by spirometry [forced expiratory volume/s $\left.\left(\mathrm{FEV}_{1}\right)\right]$, using inhalation of metacholine or citric acid mostly in asthma and chronic obstructive pulmonary disease (COPD). AspR has been described in cats (Tomori and Widdicombe, 1969) and its bronchodilatory effects were reproduced in adults with bronchial asthma (Legath et al., 2013). The CR hyper-sensitivity to capsaicin inhalation in asthmatic children was also decreased by proceeding voluntary sniffs (Pecova et al., 2013). Determination of inspiratory and/or expiratory muscle strength (EMS) also has a great diagnostic and therapeutic importance, mainly in severe respiratory and neuromuscular diseases. Sniff nasal inspiratory pressure (SNIP) represents a more simple method than the measurement of esophageal or oral maximal inspiratory and expiratory pressures (MIP and MEP) in patients with motor neuron disease (Choudri et al., 2000). The assessment of SNIP was successfully used as a simple alternative to MIP (Prigent et al., 2004). In COPD, in addition to the more complicated measurement of MIP, the traditional sniff maneuver and its provocation by cervical magnetic stimulation were used for determination of maximal diaphragm strength (Martinez-Lorens et al., 2006). The sniff maneuver, documented by measurement of SNIP, predicted and even prolonged the survival of patients with amyotrophic lateral sclerosis (Morgan et al., 2005) and facilitated weaning from mechanical ventilation (Moodie et al., 2011). Acute cardio-respiratory effects of EMS application were analyzed recently by Laciuga et al. (2012).

Experiments in cats indicated that mechanical stimulation of trachea evoked a cough reaction, which in $2 / 3$ of cases started with ExpR-like response, which was weaker, and has a lower frequency than the typical ExpR from the larynx (Poliacek et al., 2008). The measurement of EMS could be useful for quantification and differentiation of the efficacy of ExpR evoked by stimuli from the 
larynx comprising laryngo-constriction and the expiration-like reflex and CR from the tracheo-bronchial area. There may be a difference in reaction to airway sensory stimuli evoking ExpR with the immediate inhibitory effect on inspiration and the strong $\mathrm{CR}$, starting with a DI, which might contribute to the aspiration of infected materials into the lungs. Both the lower frequency and intensity of ExpR-like response from the tracheo-bronchial area depends on the momentary excitability of the brainstem generators for inspiration and expiration, respectively, which decreases during the pertinent inspiratory and expiratory phase, reflecting the instantaneous lung volume. However, the prevalence and intensity of activity of the pertinent generator will depend on the character and grade of the respiratory drive (McCrimmon and Alheid, 2007).

\section{AIRWAY REFLEXES AND BREATHING MANEUVERS IN PATHOLOGICAL CONDITIONS}

In addition to characterization of the mechanisms and effects of different respiratory reflexes, their modifications, and practical applications in various pathological conditions are even more important. Particularly the transfer of results, proved in experiments to clinical practice is very prospective. Such situation was analyzed during a workshop: "Tuning the cough center," which may manifest by stimulation, inhibition, sensitization, desensitization, or modification of the pattern of respiratory muscular contraction. For example, the main pulmonary afferent inputs, related to tuning the cough center are the cough receptors themselves, RARs, SARs, bronchial and pulmonary C fibers, and A $\delta$ fibers. Therefore, the "cough reflex" is not a stereotyped response with single pattern, but is a range of responses, which can be modulated by a large variety of neural inputs substantially contributing to respiratory plasticity (Widdicombe et al., 2011a).

The loaded respiratory muscles have an exceptional potential to increase their activity (Ross et al., 2007), which can contribute to the prevention of respiratory insufficiency during the development of cardio-respiratory failure. Recent studies indicate that reduced respiratory neuronal activity elicits a unique form of plasticity in respiratory motor control, termed as inactivityinduced phrenic motor facilitation. It can be triggered by inhibition of breathing lasting even for $30 \mathrm{~min}$, resulting from severe hypocapnia provoked by preceding hyperventilation, but also by very deep anesthesia, reflex vagal inhibition, and severe hypoxia. This may result in exaggerated activation of the brainstem generator for inspiration causing a facilitation of the inspiratory muscle activity. This situation can manifest with development of crossed phrenic phenomenon after spinal cord hemi-section or injury (Goshgarian, 2003), or as light-induced rescue of breathing after spinal cord injury (Alilain et al., 2008). Various forms of respiratory plasticity induced by intermittent hypoxia, which interact and ultimately impact on breathing stability, were investigated by Mateika and Narwani (2009). The mechanism of the reduced respiratory neural activity which elicits phrenic motor facilitation is analyzed more in detail by Mahamed et al. (2011).

It would have a great practical importance to test, if AspR and other SIs, or sniffing as their voluntary counterpart, could restore disrupted breathing, caused by various types of asphyxia. It is probable that the inactivity-induced facilitation of phrenic motoneurones has similar mechanisms as provocation of gasping respiration. The very resistant AspR persists even during the stage of pre-mortal gasping at least in cats (Jakus et al., 1987; Tomori et al., 2010). This allows a presumption that repeated AspRs and similar reflex SIs might provoke facilitation after a shorter period of breathing inactivity, rather than after a longer-lasting development of spontaneous gasping. Voluntary sniffs as counterparts of AspR might have similar restorative and resuscitative effects, particularly when applied at the beginning of spontaneous inspiration if present, when the inspiratory drive is maximal (Marek et al., 2008). Therefore, testing of the potential of AspR, ExpR, CR, and their voluntary counterparts for normalization and renewal of several functional disorders and even auto-resuscitation is an important goal.

The $C R$ with the ExpR and swallowing provides the basic respiratory defense mechanisms preventing development of dangerous aspiration pneumonia, and these behaviors frequently fail particularly in elderly patients and in chronic respiratory infections. In elderly people the life-threatening pneumonia is very high, particularly in patients with multiple or bilateral cerebral infarction. The mechanism of aspiration pneumonia can be explained in part by the SP theory, supported by 7-times lower level of SP in sputum of such patients compared to healthy adults (Nakagawa et al., 1995). Experiments indicated that repeated applications of a dopamine D1 receptor antagonist inhibits swallowing reflex in guinea pigs (Jia et al., 1998). The decreased dopamine production may reduce the expression of SP at the glossopharyngeal nerve and at the cervical parasympathetic ganglion of the sensory branch of that nerve, representing the afferent neural pathways in cough (Karlsson et al., 1998). The depression of SP in insular cortex is thought to be associated with impairment of swallowing and consecutively of the CR and probably also the ExpR, which is the main reflex that should prevent aspiration (Ebihara and Ebihara, 2011). Their novel strategy for preventing aspiration pneumonia is based on a support of swallowing, coughing, and ExpR via insular cortex stimulation by thermal and olfactory stimuli in the food and by frequent oral care.

\section{THE URGE-TO-COUGH MODEL}

The CR consists of three motor stages which may be modified by pathological conditions and three sensory stages which can be influenced voluntarily. In conscious adults, the urge-to-cough model allows prevention and treatment of unwanted aspirations, connected with impairment of swallowing and coughing as well as with DIs, which may contribute to development of dangerous aspiration pneumonia and other complications in patients at risk (Davenport, 2008). The onset of cough caused by hyperreactivity can be inhibited by behavioral methods in addition to pharmaceutical treatment. In gastro-esophageal reflux or intrusion of foreign substances into the pharynx with or without aspiration to the larynx and lower airways, reflex or voluntary swallowing and a prompt expiratory effort is required for expulsion of irritant substances. Stimulation of the oropharyngeal mucosa by air puff pressure pulses of $-25 \mathrm{~cm} \mathrm{H}_{2} \mathrm{O}$ in healthy adults-induced urgeto-cough, which only in $81 \%$ was followed by a CR. This indicates that the threshold for motor effect is higher, than for the sensory reaction (Wheeler-Hegland et al., 2011). In addition, healthy 
adults can modify voluntarily the CR motor output induced by inhalation of $200 \mu \mathrm{mol}$ capsaicin (Hegland et al., 2012). A voluntary suppression of urge-to-cough may prevent unwanted coughing with DI and a subsequent risk for development of aspiration pneumonia. The onset of the cough expiratory effort may be also postponed and preceded by a breath-holding and swallowing of the bolus to the esophagus (Vertigan and Gibson, 2011).

For therapy of neuromuscular and respiratory disorders and diseases both expiratory and inspiratory muscle strength training proved to be a very promising method. For example, EMST for improvement of hypofunctional $\mathrm{CR}$ in older people, particularly with Parkinson's disease (PD). Dysphagia is the main cause of aspiration pneumonia and death in PD. IMST was used to improve weaning from mechanical ventilation. The mechanism of disorders of defensive mechanisms may be explained by improved hyolaryngeal complex movement (Troche et al., 2010). Cough provides high expiratory airflows to aerosolize and remove material that cannot be adequately removed by ciliary action. Cough and ExpR are particularly important for clearing foreign particles from the airways in those with dysphagia who may be at risk for aspiration pneumonia. After 4 weeks of EMST there was a significant decrease in the compressive phase duration and expiratory phase rise time, resulting in a significant increase in cough volume acceleration. As well, there was a significant decrease in the swallowing penetration/aspiration score, indicating that EMST is associated with improvement of both coughing and swallowing (Pitts et al., 2009). Analysis of the cortical gating mechanism indicated that oropharyngeal mechanosensation is not gated like other somatosensory systems (Poliacek et al., 2009a,b; WheelerHegland et al., 2011).

\section{EVALUATION OF VARIOUS COMPONENTS OF AIRWAY REFLEXES AND THEIR VOLUNTARY COUNTERPARTS}

The particular phases of AspR, ExpR, and CR could be visualized by a stereo camera and calcium sensitive dyes in in vitro brainstem preparation (Koshiya and Smith, 1999). Such three-dimensional visualization can support better understanding of their mechanisms. The motor pattern of various airway defensive behaviors have spatiotemporal regulation. In the case of CR there is a separate regulation of the amplitude and temporal features of cough motor pattern. The time of cough expiration is determined by the second non-active phase of cough expiration (Bolser et al., 2006).

Functional magnetic resonance imaging (fMRI) and other methods were already tested for evaluation of sniffing and coughing (Simonyan et al., 2007). In spite of the undefined distinction between sniffing induced by odorous stimulation and AspR from the NPh (Widdicombe, 2011), sniffs and prompt forced expirations as voluntary counterparts of AspR and ExpR can provide an environmental control. The patients may be able to use these airflow behaviors to control/activate computer controlled devices. Therefore, even the severely disabled patients can communicate using a computer and regulate the movement of their wheelchairs, as was proved by Plotkin et al. (2010). Such activity can be realized in paraplegics by persistent voluntary sniffs and ExpRs, acting via UA reflexes representing binary symbols, that enable control of devices assisting in everyday activities.

fMRI revealed a preparatory activity to movement in the premotor area of the brain without a successive motor effect in the vegetative state, which was observed in some patients after verbal instructions (Simonyan et al., 2007). Marked activity was observed in the pre-motor cortex in vegetative state also by Beckinschtein et al. (2011). The persisting AspR might allow differentiation of patients in a vegetative state by the presence of activity in the pre-motor area of brain in fMRI on the instruction to move the hand, from non-reacting patient with brain death. Cardiogenic oscillation and ventilatory auto-triggering observed by Arbour (2009), and other signs of persistent vitality, detected by Wijdicks et al. (2010), could also be tested using airway reflexes. Therefore, similar activities might also be observed by fMRI after provocation of AspR by mechanical means even in more severe disorders of consciousness without voluntary but persisting reflex signs. Since AspR persists even in the stage of pre-mortal gasping at least in cats (Jakus et al., 1987; Tomori et al., 2010), the procedure might allow exclusion of brain death in selected and indicated cases of moribund patients.

\section{CONCLUSION}

In our long-term study of airway reflexes two distinct reflexes were described in cats in addition to systematic analysis of cough. The sniff- and gasp-like AspR evoked by nasopharyngeal stimulation resembles gasping, which resuscitated $\sim 15 \%$ of moribund infants and animals according to reserves of their vital functions. AspR in cats was proved to reverse hypoxic apnoea, laryngospasm, bronchospasm, and even transient comatose states. AspR followed by ExpR or a prompt cough effort may provide sufficient venous return to the heart and thus support the cerebral perfusion, providing CPCR, resembling auto-resuscitation by gasping. AspR strongly activates the brainstem inspiratory generator and ExpR the expiratory one. They can reverse many hypo- and hyper-functional disorders by influencing their central control mechanisms. Esophageal MIP and MEP and a very simple SNIP are often measured in asthma, COPD, weaning from non-invasive ventilation and even in Amyotrophic lateral sclerosis. EMST proved to be a useful method for support of airway defense by improvement of the swallowing and cough for prevention of aspiration pneumonia, particularly in patients with PD. Sniffs and strong expirations held as voluntary counterparts of AspR and ExpR might help to explain and quantify their presupposed reflex effects in clinical studies of various respiratory, cardiovascular, and neuromuscular diseases. Such breathing maneuvers providing a binary symbol (sniffs and prompt expirations), might enable severely disabled patients to communicate using a computer and control their wheelchair movement. Several effects are currently tested in animal experiments and human studies for implementation of the useful potential of airway reflexes and their voluntary counterparts.

\section{ACKNOWLEDGMENTS}

The implementation of experiences obtained during the complex study of airway reflexes summarized in a concentrated 
form in this review, was possible by close cooperation with Prof. emeritus Imrich Ivanco MD, Ph.D., and late Prof. Juraj Korpas, MD, Dr. Sc. at the Faculty of Medicine PJ Safarik University, Kosice, Slovakia and later with Juraj Korpas, Prof. Kamil Javorka, MD, Dr. Sc., Prof. Albert Stransky, MD, Ph.D.,

\section{REFERENCES}

Addington, W. R., Stephens, R. E., Widdicombe, J. G., Anderson, J. W., and Rekab, K. (2003). Effect of tartaric acid-induced cough on pulmonary function in normal and asthmatic humans. Am. J. Phys. Med. Rehabil. 82, 374-378.

Addington, W. R., Stephens, R. E., Widdicombe, J. G., and Rekab, K. (2005). Effect of stroke location on the laryngeal cough reflex and pneumonia risk. Cough 1:4. doi: 10.1186/ 1745-9974-1-4

Alilain, W., Li, X., Horn, K. P., Dhingra, R., Dick, T. E., Herlitze, S., et al. (2008). Light-induced rescue of breathing after spinal cord injury. J. Neurosci. 28, 11862-11870.

Arbour, R. (2009). Cardiogenic oscillation and ventilator autotriggering in brain-dead patients: a case series. Am. J. Crit. Care 18, 488-495.

Arita, H., Oshima, T., Kita, I., and Sakamoto, M. (1994). Generation of hiccup by electrical stimulation in medulla of cats. Neurosci. Lett. 175, 67-70.

Batsel, H., and Lines, A. J. (1973). Bulbar respiratory neurons participating in the sniff reflex in the cat. Exp. Neurol. 39, 469-481.

Beckinschtein, T. A., Manes, F. F., Villarreal, M., Owen, A. M., and Della-Maggiore, V. (2011). Functional imaging reveals movement preparatory activity in the vegetative state. Front. Hum. Neurosci. 5:5. doi: 10.3389/fnhum. 2011.00005

Benacka, R., and Tomori, Z. (1995). The sniff-like aspiration reflex evoked by electrical stimulation of the nasopharynx. Respir. Physiol. 102, 163-174.

Benacka, R., and Tomori, Z. (1999). Stimulation within nasal philtre induces gasp-like reaction and reversal of hypoxic apnoeic episodes. Eur. Respir. J. 14, 225.

Bolser, C. D., Poliacek, I., Jakus, J., Fuller, D. D., and Davenport, P. W. (2006). Neurogenesis of cough, other airway defensive behaviors and breathing. A holarchical system? Respir. Physiol. Neurobiol. 152, 255-265.

Canning, B. J., and Mazzone, S. B. (2005). "Afferent pathways regulating the cough reflex," in Lung
Biology in Health and Disease: Acute and Chronic Cough, eds A. E. Redington and A. H. Morice (Boca Raton, FL: Taylor and Francis Group, LLC), 25-48.

Choudri, M. B., Liu, C., Watson, L., Jefferson, D., and Kinnear, W. J. (2000). Sniff nasal inspiratory pressure as a marker of respiratory function in motor neuron disease. Eur. Respir. J. 15, 539-542.

Davenport, P. (2008). Urge to cough: what can it teach us about cough. Lung 186(Suppl. 1), 107-111.

Donic, V., Benacka, R., Kurpas, M., and Tomori, Z. (1992). Pressure stimulation applied into the upper airway can modify breathing pattern in cats. Eur. Respir. J. 5, 457.

Ebihara, S., and Ebihara, T. (2011). Cough in the elderly: a novel strategy for preventing aspiration pneumonia. Pulm. Pharmacol. Ther. 24, 318-323.

Eckert, D. J., McEvoy, R. D., George, K. E., Thomson, K. J., and Catcheside, P. G. (2007). Genioglossus reflex inhibition to upper-airway negative pressure stimuli during wakefulness and sleep in healthy males. J. Physiol. 582, 1193-1205.

Eckert, D. J., Sabolsky, J. P., Jordan, A S., White, D. P., and Malhotra, A. (2010). A secondary reflex suppression phase is present in genioglossus but not tensor palatini in response to negative upper airway reflex. J. Appl. Physiol. 108, 1619-1624.

Fass, R., Higa, A., Kodner, A., and Mayer, E. A. (1997). Stimulus and site specific inductions of hiccups in the oesophagus of normal subjects. Gut 41, 590-593.

Fung, M. L., St. John, W. M., and Tomori, Z. (1994). Reflex recruitment of medullary gasping mechanisms in eupnoea by pharyngeal stimulation in cats. J. Physiol. 475, 519-529.

Goldstein, R. (1999). Simple method for curing hiccups. Can. Fam. Physician 45, 1459.

Goshgarian, H. G. (2003). The crossed phrenic phenomenon: a model for plasticity in the respiratory pathways following spinal cord injury. J. Appl. Physiol. 94, 795-810.

Hegland, K. W., Bolser, D. C., and Davenport, P. W. (2012). Volitional

and others at the Jessenius Faculty of Medicine in Martin, Comenius University, Bratislava, Slovakia, as well as with late Prof. John G. Widdicombe from Oxford University and later at London University, UK. Many thanks for their valuable collegial cooperation.

control of reflex cough. J. Appl. Physiol. 113, 39-46.

Horner, R. L., Innes, J. A., Murphy, K. and Guz, A. (1991a). Evidence for reflex upper airway dilator muscle activation by sudden negative airway pressure in man. J. Physiol. 436, 15-29.

Horner, R. L., Innes, J. A., Holden, H. B., and Guz, A. (1991b). Afferent pathway(s) for pharyngeal dilatory reflex to negative pressure in man: a study of upper airway anesthesia. J. Physiol. 436, 31-44.

Jakus, J., Halasova, E., Poliacek, I., Tomori, Z., and Stransky, A. (2004a). Brainstem areas involved in the aspiration reflex: c-Fos study in anesthetized cats. Physiol. Res. 33, 703-717.

Jakus, J., Tomori, Z., and Stransky, A. (2004b). Neuronal Determinants of Breathing, Coughing and Other Motor Behaviours. Martin: Wist, 333.

Jakus, J., Tomori, Z., Boselova, L., Nagyova, B., and Kubinec, V. (1987). Respiration and airway reflexes after transversal brain stem lesions in cats. Physiol. Bohemoslov. 36, 329-340.

Janczewski, W. A., and Feldman, J. L. (2006a). Distinct rhythm generators for inspiration and expiration in the juvenile rat. J. Physiol. 570, 407-420.

Janczewski, W. A., and Feldman, J. L. (2006b). Novel data supporting the two respiratory rhythm oscillator hypothesis. J. Neurophysiol. 96, 1-2.

Javorka, K., Tomori, Z., and Zavarská, L. (1980). Protective and defensive airway reflexes in premature infants. Physiol. Bohemoslov. 29, 29-35.

Jia, Y. X., Sekizawa, K., Ohrui, T., Hakayama, K., and Sasaki, H. (1998). Dopamine D1 receptor antagonist inhibits swallowing reflex in guinea pigs. Am. J. Physiol. 274(1 Pt 2), 76-80.

Kahrilas, P. J., and Shi, G. (1997). Why do we hiccup? Gut 41, 712-713.

Karlsson, J. A., Sant'Ambrogio, G., and Widdicombe, J. (1998). Afernet neural patways in cough and reflex bronchoconstriction. J. Appl. Physiol. 65, 1007-1023.

Kondo, T., Toyooka, H., and Arita, H. (2003). Hiccup reflex is mediated by pharyngeal branch of glossopharyngeal nerve in cats. Neurosci. Res. 47, 317-321.

Korpas, J. (1972). Expiration reflex from the vocal folds. Physiol. Bohemoslov. 21, 671-675.

Korpas, J. (1979). "The expiration reflex," in Cough and Other Respiratory Reflexes, eds J. Korpas and Z. Tomori (Basel: Karger), 189-217.

Korpas, J., and Tomori, Z. (1979). Cough and Other Respiratory Reflexes. Basel: Karger.

Koshiya, N., and Smith, J. C. (1999). Neuronal pacemaker for breathing visualized in vitro. Nature 400, 360-363.

Laciuga, H., Davenport, P., and Sapienza, C. (2012). The acute effects of a single session of expiratory muscle strength training on blood pressure, heart rate, and oxygen saturation in healthy adults. Front. Physio. 3:48. doi: 10.3389/fphys.2012.00048

Legath, L., Perecinsky, S., Varga, M., Orolin, M., Tomori, Z., and Legath, J. (2013). Latent airway hyperresponsivenes: a phenomenon bordering bronchial asthma definition. Adv. Exp. Med. Biol. 755, 97-101.

Leiter, J. C., and Böhm, I. (2007). Mechanisms of the patho-genesis in the sudden infant death syndrome (SIDS). Respir. Physiol. Neurobiol. 159, 127-138.

Mahamed, S., Strey, K. A., Metchell, G. S., and Baker-Herman, T. L. (2011) Reduced respiratory neural activity elicits phrenic motor facilitation. Respir. Physiol. Neurobiol. 175, 303-309.

Marek, W., Muckenhoff, K., and Prabhakar, N. R. (2008). Significance of pulmonary vagal afferents for respiratory muscle activity in the cat. J. Physiol. Pharmacol. 59(Suppl. 6), 407-420.

Martinez-Lorens, J., Coronell, C., Ramírez-Sarmiento, A., Orozco-Levi, M., Espadaler, J. M., Bautista Gáldiz, J., et al. (2006). Determination of maximal diaphragm strength in chronic obstructive pulmonary disease: cervical magnetic stimulation versus traditional sniff maneuver. Arch. Bronconeumol. 42, 509-515. 
Mateika, J. H., and Narwani, G. (2009). Intermittent hypoxia and respiratory plasticity in humans and other animals: does exposure to intermittent hypoxia promote or mitigate sleep apnoea? Exp. Physiol. 94, 279-296.

McCrimmon, D. R., and Alheid, G. F. (2007). Reflexively inhibiting respiratory drive. J. Physiol. 580, 3.

McNamara, F., Lijovska, A. S., and Thach, B. T. (2002). Spontaneous arousal activity in infants during NREM and REM sleep. J. Physiol. 538, 263-269.

Moodie, L. H., Reeve, J. C., Vermeulen, N., and Elkins, M. R. (2011). Inspiratory muscle training to facilitate weaning from mechanical ventilation: protocol for a systematic review. BMC Res. Notes 4:283. doi: 10.1186/1756-0500-4-283

Morgan, R. K., McNally, S., Alexander, M., Conroy, R., Hardiman, O., and Costello, R. W. (2005). Use of Sniff nasal-inspiratory force to predict survival in amyotrophic lateral sclerosis. Am. J. Respir. Crit. Care Med. $171,269-274$.

Nakagawa, T., Ohrui, T., Sekizawa, K., and Sasaki, H. (1995). Sputum substance $\mathrm{P}$ in aspiration pneumonia. Lancet 345, 1447.

Nail, B. S., Sterling, G. M., and Widdicombe, J. G. (1969). Epipharyngeal receptors responding to mechanical stimulation. J. Physiol. 204, 91-98.

Newsom Davis, J. (1970). An experimental study of hiccup. Brain 93, 851-872.

Oshima, T., Sakamoto, M., and Arita, H. (1994). Hiccuplike response elicited by mechanical stimulation of dorsal epipharynx of cats. J. Appl. Physiol. 76, 1885-1895.

Oshima, T., Sakamoto, M., Tatsuta, H., and Arita, H. (1998). GABAergic inhibition of hiccup-like reflex induced by electrical stimulation in medulla of cats. Neurosci. Res. 30, 287-293.

Pecova, R., Michnova, T., Fabry, J., Zatko, T., Neuschlova, M., Klco, P., et al. (2013). Deep nasal inspirations increase the cough threshold in children in mild asthma. Adv. Exp. Med. Biol. 755, 65-69.

Pena-Ortega, F. (2012). Tonic neuromodulation of the inspiratory rhythm generator. Front. Physio. 3:253. doi: 10.3389/fphys.2012. 00253

Pitts, T., Donald Bolser, M. A., Rosenbek, J., Troche, M., Okun, M. S., and Sapienza, C. (2009). Impact of expiratory muscle strength training on voluntary cough and swallow function in Parkinson disease. Chest 135, 1301-1308.

Plotkin, A., Sela, L., Weissbrod, A., Kahana, R., Haviv, L., Yeshurun, Y., et al. (2010). Sniffing enables communication and environmental control for the severely disabled. Proc. Natl. Acad. Sci. U.S.A. 107, 14413-14418.

Poliacek, I., Jakus, J., Simera, M., Barani, H., Visnovcova, N., Halasova, E., et al. (2009a). Excitability and rhythmicity of tracheobronchial cough is altered by aspiration reflex in cats. J. Physiol. Pharmacol. 60, 105-110.

Poliacek, I., Tomori, Z., Simera, M., Barani, H., Visnovcova, N., Halasova, E., et al. (2009b). Provocation of aspiration reflexes and their effects on the pattern of cough and reflex apnea in cats. J. Physiol. Pharmacol. 60, 99-104.

Poliacek, I., Rose, M. J., Corrie, L. W., Wang, C., Jakus, J., Barani, H., et al. (2008). Short reflex expirations (expiration reflexes) induced by mechanical stimulation of the trachea in anesthetized cats. Cough 4:1. doi: 10.1186/1745-9974-4-1

Poliacek, I., Stransky, A., Jakus, J., Barani, H., Tomori, Z., and Halasová, E. (2003). Activity of the laryngeal abductor and adductor muscles during cough, expiration and aspiration reflexes in cats. Physiol. Res. 52, 749-762.

Prigent, H., Lejaille, M., Falaize, L., Louis, A., Ruquet, M., Fauroux, B., et al. (2004). Assessing inspiratory muscle strength by sniff nasal inspiratory pressure. Neurocrit. Care 1, 475-478.

Ristagno, G., Tang, W., Sun, S., and Weil, M. H. (2007). Spontaneous gasping produces carotid blood flow during untreated cardiac arrest. Resuscitation 75, 366-371.

Ross, E. Z., Nowicky, A. V., and McConnel, A. K. (2007). Influence of acute inspiratory loading upon diaphragm motor-evoked potentials in healthy humans. J. Appl. Physiol. 102, 1883-1890.

Salem, M. R., Baraka, A., Rattenborg, C. C., and Holaday, D. A. (1967). Treatment of hiccups by pharyngeal stimulation in anaesthetized and conscious subjects. JAMA 202, 32-36.

Sant'Ambrogio, G., Sant'Ambrogio, F. B., and Davies, A. (1984). Airway receptors in cough. Bull. Eur. Physiophatol. Respir. 20, 43-47.

Shiba, K., Satoh, I., Kobayashi, N., and Hayashi, F. (1999). Multifunctional laryngeal motoneurons: an intracellular study in the cat. J. Neurosci. 19, 2717-2727.
Simonyan, K., Saad, Z. S., Loucks, T. M., Poletto, C. J., and Ludlow, C. L. (2007). Functional neuroanatomy of human voluntary cough and sniff production. Neuroimage 37 , 401-409.

Sridhar, R., Thach, B. T., Kelly, D. H., and Henslee, J. A. (2003). Characterization of successful and failed autoresuscitation in human infants, including those dying of SIDS. Pediatr. Pulmon. 36, 113-122.

Szaboova, E., Holoubek, D., Tomori, Z. Szabo, P., Donic, V., and Stancak, B. (2013). Severity of noscturnal cardiac arhytmias corelates with instensity of sleep apnea in man. Adv. Exp. Med. Biol. 755, 155-168.

Tan, W., Janczewski, W. A., Yang, P., Shao, X. M., Callaway, E. M., and Feldman, J. L. (2008). Silnencing preBötzinger complex somatostatin-expressing neurons induced persistent apnea in awake rat. Nat. Neurosci. 11, 538-540.

Tan, W., Pagliardiny, S., Yang, P., Janczewski, W. A., and Feldman, J. L. (2010). Projections of preBötzinger complex neurons in adults rats. J. Comp. Neurol. 518, 1862-1878.

Tatar, M., Hanacek, J., and Widdicombe, J. (2008). The expiration reflex from the trachea and bronchi. Eur. Respir. J. 31, 385-390.

Thach, B. T. (2005). The role of respiratory control disorders in SIDS. Respir. Physiol. Neurobiol. 149, 343-353.

Thach, B. T., Gershan, W. R., and Jacobi, M. S. (1991). "Control of breathing during asphyxia and autoresuscitation," in Developmental Neurobiology of Breathing, eds G. G. Haddad and J. P. Farber (New York, NY; Basel: Marcel Dekker), 681-699.

Thach, B. T., Menon, A. P., and Schefft, G. L. (1989a). Effect of negative upper airway pressure on pattern of breathing in sleeping infants. J. Appl. Physiol. 66, 1599-1605.

Thach, B. T., Schefft, G. L., Pickens, D. L., and Menon, A. P. (1989b). Influence of upper airway negative pressure reflex on response to airway occlusion in sleeping infants. J. Appl. Physiol. 67, 749-755.

Tomori, Z. (1965). Pleural, tracheal and abdominal pressure variations in defensive and pathologic reflexes of the respiratory tract. Physiol. Bohemoslov. 14, 84-95.

Tomori, Z. (1979a). "Physiology of the cough reflex," in Cough and Other Respiratory Reflexes, eds J. Korpas and Z. Tomori (Basel: Karger), 15-80.

Tomori, Z. (1979b). "The sniff-like aspiration reflex," in Cough and Other Respiratory Reflexes, eds J. Korpas and Z. Tomori (Basel: Karger), 234-250.

Tomori, Z., Benacka, R., and Donic, V. (1998). Mechanisms and clinicophysiological implications of the sniff- and gasp-like aspiration reflex. Respir. Physiol. 114, 83-98.

Tomori, Z., Benacka, R., Donic, V. and Jakus, J. (2000). Contribution of upper airway reflexes to apnoea reversal, arousal, and resuscitation. Monaldi Arch. Chest Dis. 55, 398-403.

Tomori, Z., Benacka, R., Donic, V., and Tkacova, R. (1991). Reversal of apnoea by aspiration reflex in anaesthetized cats. Eur. Respir. J. 4, 1117-1125.

Tomori, Z., Fung, M. L., Donic, V., Donicova, V., and St. John, W. M. (1995a). Power spectral analysis of respiratory reflexes to pharyngeal stimulation in cats: comparisons with eupnoea and gasping. J. Physiol. 485, 551-559.

Tomori, Z., Kurpas, M., Donic, V., and Benacka, R. (1995b). Reflex reversal of apnoeic episodes by electrical stimulation of upper airway cats. Respir. Physiol. 102, 175-185.

Tomori, Z., Lemakova, S., Gromysz, H., and Stransky, A. (1976). "Changes in the respiratory centre activity elicited by mechanical stimulation of the airways," in Respiratory Centres and Afferent Systems, Vol. 59, ed B. Duron (Paris: INSERM), 129-138.

Tomori, Z., Poliacek, I., Jakus, J., Widdicombe, J. G., Donic, V., Benacka, R., et al. (2010). Distinct generators for aspiration and expiration reflexes: localization, mechanisms and effects. J. Physiol. Pharmacol. 61, 5-12.

Tomori, Z., and Widdicombe, J. G. (1969). Muscular, bronchomotor and cardiovascular reflexes elicited by mechanical stimulation of the respiratory tract. J. Physiol. 200, 25-49.

Troche, M. S., Okun, M. S., Rosenbek, J. C., Musson, N., Fernandez, H. H., Rodriguez, R., et al. (2010). Aspiration and swallowing in Parkinson disease and rehabilitation with EMST. Neurology 75, 1912-1919.

Vertigan, A. E., and Gibson, P. D. (2011). Urge to cough and its application to the behavioral treatment of cough. Bratisl. Lek. Listy 112, 102-108. 
Wheeler-Hegland, K., Pitts, T., and Davenport, P. W. (2011). Cortical gating of oropharyngeal sensory stimuli. Front. Physio. 1:167. doi: 10.3389/fphys.2010.00167

Widdicombe, J. G. (2006). Historical perspective: reflexes from the lungs and airways. J. Appl. Physiol. 101, 628-634.

Widdicombe, J. G. (2011). "Reflexes from the upper respiratory tract -the respiratory system," in Comprehensive Physiology, Chapter 11, (Weinheim, Germany: Wiley online library), 363-394.

Widdicombe, J. G., Addington, W. R., Fontana, G. A., and Stephens, R. E. (2011a). Voluntary and reflex cough and the expiration reflex: implications for aspiration after stroke. Pulm. Pharmacol. Ther. 24, 312-317.

Widdicombe, J. G., Tatar, M., Fontana, G., Hanacek, J., Davenport, P., Lavorini, F., et al. (2011b).
Workshop: tuning the 'cough center'. Pulm. Pharmacol. Ther. 24, 344-352.

Wijdicks, E. F. M., Varelas, P. N. Gronseth, G. S., and Greer, D. M. (2010). Evidence based guidelines update: determining brain death in adults. Neurology 74, 1911-1918.

Wulbrand, H., McNamara, F., and Thach, B. T. (2008). The role of arousal related breinstem reflexes in causing recovery from upper airway occlusion in infants. Sleep 31 833-840.

Wulbrand, H., Von Zezschwitz, G., and Bentele, K. H. (1995). Submental and diaphragmatic muscle activity during and at resolution of mixed and obstructive apneas and cardiorespiratory arousal in preterm infants. Pediatr. Res. 38, 298-305.

Xie, J., Weil, M. H., Sun, S., Yu, T., and Tang, W. (2004). Spontaneous gasping generates cardiac output during cardiac arrest. Crit. Care Med. 32, 238-240.

Conflict of Interest Statement: Prof Zoltan Tomori and Prof. Viliam Donic are consultants of Nasophlex, Slovakia from 2009 with no influence on the present paper. Three patent applications were submitted by Gerrit deVos and Zoltan Tomori with the help of Nasophlex, Slovakia for provocation of AspR or spasmodic inspirations: (1) by stimulation of the nasopharynx, (2) by stimulation of the nasal philter, and (3) by stimulating a superficial point of a human ear, which are now tested in animal and clinical studies. The other authors declare that the research was conducted in the absence of any commercial or financial relationships that could be construed as a potential conflict of interest.
Received: 30 April 2012; accepted: 26 November 2012; published online: 14 December 2012.

Citation: Tomori Z, Donic V, Benacka R, Gresova S, Peregrim I, Kundrik M, Pallayova M and Jakus J (2012) Reversal of functional disorders by aspiration, expiration, and cough reflexes and their voluntary counterparts. Front. Physio. 3:467. doi: 10.3389/fphys.2012.00467 This article was submitted to Frontiers in Respiratory Physiology, a specialty of Frontiers in Physiology.

Copyright (C) 2012 Tomori, Donic, Benacka, Gresova, Peregrim, Kundrik, Pallayova and Jakus. This is an openaccess article distributed under the terms of the Creative Commons Attribution License, which permits use, distribution and reproduction in other forums, provided the original authors and source are credited and subject to any copyright notices concerning any third-party graphics etc. 